TITLE:

\title{
Ultrasonic evaluation of fatigue cracks at the wheel seat of a miniature wheelset
}

$\operatorname{AUTHOR}(\mathrm{S})$ :

Makino, Kazunari; Biwa, Shiro; Sakamoto, Hiroshi; Yohso, Jiro

\section{CITATION:}

Makino, Kazunari ... [et al]. Ultrasonic evaluation of fatigue cracks at the wheel seat of a miniature wheelset. Nondestructive Testing and Evaluation 2012, 27(1): 29-46

ISSUE DATE:

2012-03

URL:

http://hdl.handle.net/2433/199251

\section{RIGHT:}

This is an Accepted Manuscript of an article published by Taylor \& Francis in "Nondestructive Testing and Evaluation" on 2012, available online: http://www.tandfonline.com/10.1080/10589759.2011.577430.; この論文は出版社版でありま せん。引用の際には出版社版をご確認じ利用ください。; This is not the published version. Please cite only the published version. 
This article appeared as:

K. Makino, S. Biwa, H. Sakamoto and J. Yohso, Ultrasonic evaluation of fatigue cracks at the wheel seat of a miniature wheelset, Nondestructive Testing and Evaluation, Vol. 27 (2012), pp. 29-46.

\title{
Ultrasonic Evaluation of Fatigue Cracks at the Wheel Seat of a Miniature Wheelset
}

\author{
Kazunari Makino ${ }^{a}$, Shiro Biwa ${ }^{b}$, Hiroshi Sakamoto ${ }^{a}$ and Jiro Yohso ${ }^{a}$
}

a: Vehicle Structure Technology Division, Railway Technical Research Institute, 2-8-38, Hikari-cho, Kokubunji-shi, Tokyo 185-8540, Japan

b: Department of Aeronautics and Astronautics, Graduate School of Engineering, Kyoto University, Katsura, Nishikyo-ku, Kyoto 615-8540, Japan

Corresponding author: Kazunari Makino (makino.kazunari.34@rtri.or.jp)

\begin{abstract}
Ultrasonic testing of axles is an important issue regarding the integrity assessment of railway vehicles. In this study, several aspects of the ultrasonic evaluation of fatigue cracks in an axle are examined experimentally. Namely, the effects of (i) the bending load applied to the axle, (ii) the presence of a wheel fitted to the axle, and (iii) the nominal frequency and the type of an ultrasonic probe, on the measured ultrasonic echo height of a crack are examined. To this aim, two fatigue cracks of different depths were developed at the wheel seat of a miniature wheelset test piece by rotating bending, and inspected using angle probes and grazing SH-wave probes under bending loads. The echo height of the cracks varied remarkably with the bending stress due to its crack opening/closing effect, accompanying some hysteresis. A possible reason for this is discussed qualitatively based on the ultrasonic wave transmission across the crack surfaces as well as the axle-wheel interface. The performances of different probes in detecting echo signals as well as estimating crack depths are compared and discussed. As a result, it is found that (i) the use of grazing SH-wave probes may be useful for the crack detection, and (ii) the application of bending load to the wheelset will be advantageous in highlighting the echo signal. The observed effect of the nominal frequency of the probe on the echo-height level is examined in a qualitative manner. Finally, the applicability of the present results to full-sized axles is discussed.
\end{abstract}

Keywords: Railway wheelset; Fatigue crack; Artificial flaw; Ultrasonic testing; Axle-wheel interface 


\section{Introduction}

On railway vehicles, wheel seats have been a potential site for axle failures due to the growth of a fatigue crack initiated by the effect of the fretting between an axle and a wheel. To prevent such damages, the axles are inspected periodically [1] and the effort to optimize the inspection interval of the axles has been made from the viewpoint of POD (probability of detection) [2,3]. There are many ways to detect the flaws ultrasonically in railway axles [4], and the inspection method and system using normal probes has been deeply studied from the viewpoint of both of the theoretical and practical aspects [5]. In Japan, recent ultrasonic axle inspection techniques, using normal or angle beams, have enabled the testing of axles in the state of a wheelset, i.e., with the wheels being fitted on them [6-8]. Such inspection techniques are also in use in Germany for example [9]. As a result, the axle breakage events caused by such a crack have been reduced substantially. When an axle is inspected in the state of a wheelset, however, there is a concern that the signal-to-noise ratio might be deteriorated due to the reduction in a crack signal and the generation of the press-fit echo $[10,11]$.

In the axle inspection, the sensitivity of an ultrasonic flaw detector is usually adjusted on the basis of the echo height of an artificial flaw. With respect to most of fatigue cracks, however, the crack tip is closed and the crack faces are in partial contact with each other. Accordingly, there could exist some differences between the echo height of a fatigue crack and that of an artificial flaw even if they have the same depth and length [12].

There have been many reports focusing on the echo-height difference between a fatigue crack and an artificial flaw depending on the stress condition at crack faces by applying the angled shear wave $[13,14]$ or the surface acoustic wave [15]. However, most of foregoing investigations employed the test pieces in the form of flat plates on which fatigue cracks were developed by e.g. a three-point bending test. There appear to be few reports that treated an ultrasonic testing of fatigue cracks developed in an axle by a rotating bending fatigue test which would better simulate more realistic service conditions [16]. Moreover, no reports seem to be available on an ultrasonic testing of fatigue cracks when they are located at an axle surface covered by a wheel, and subjected to the bending load which can cause their opening or closure.

In addition to conventional angle probes, the authors have investigated the use of a grazing shear-horizontal-wave (SH-wave) probe for the axle testing [17]. Since the vibration mode of the ultrasonic beam generated by this probe does not change by the reflection at a surface crack, there exists a possibility that the sensitivity of the crack detection would become higher with this probe. In this regard, it is important to compare the performance for the crack detection between angle probes and grazing SH-wave probes, especially in the situation when a crack in an axle lies under a fitted wheel and is subjected to a compressive stress by the bending load.

In this paper, the implications of the above-mentioned issues for the ultrasonic evaluation of fatigue cracks in an axle are examined. Namely, the effects of the presence of a fitted wheel as well as the bending load on the ultrasonic echo signal of a fatigue crack at the wheel seat are investigated using a specially prepared miniature wheelset test piece. We compare the echo heights and the waveforms when a fatigue crack is placed in crack opening or closure situations under the tensile or compressive stresses, respectively, at the wheel seat subjected to the axle bending load. We also compare these features when the miniature 
axle is fitted with a wheel or not, and when the axle is inspected by angle probes or grazing SH-wave probes, both with different nominal frequencies. In addition, an estimation of the depth of a fatigue crack is attempted by comparing the echo height of a fatigue crack to that of an artificial flaw, and the influences of the wheel fitting as well as the axle bending load on the estimated crack depth are examined.

\section{Test method}

\subsection{Test piece}

A miniature wheelset test piece as shown in Figure 1 was specially prepared and used in the present study, since the use of this miniature wheelset instead of a full-sized one enables the ultrasonic measurements to be performed more readily under the bending loading with an ordinary test machine as described below. A miniature wheel was shrink-fitted on a miniature axle, in contrast to full-sized wheelsets which are usually press-fitted. The length of a test piece was $432 \mathrm{~mm}$, the diameter of a grip section was 55 $\mathrm{mm}$ and that of a wheel seat was $57 \mathrm{~mm}$. The clearance of shrink fit was approximately $40 \mu \mathrm{m}$ in diameter and the contact pressure was estimated as approximately $85 \mathrm{MPa}$, which are similar to those for full-sized wheelsets. The maximum height of profile $R_{\mathrm{z}}$ at the surface of the axle was $3 \mu \mathrm{m}$ and that at the inner surface of the wheel was $10 \mu \mathrm{m}$.

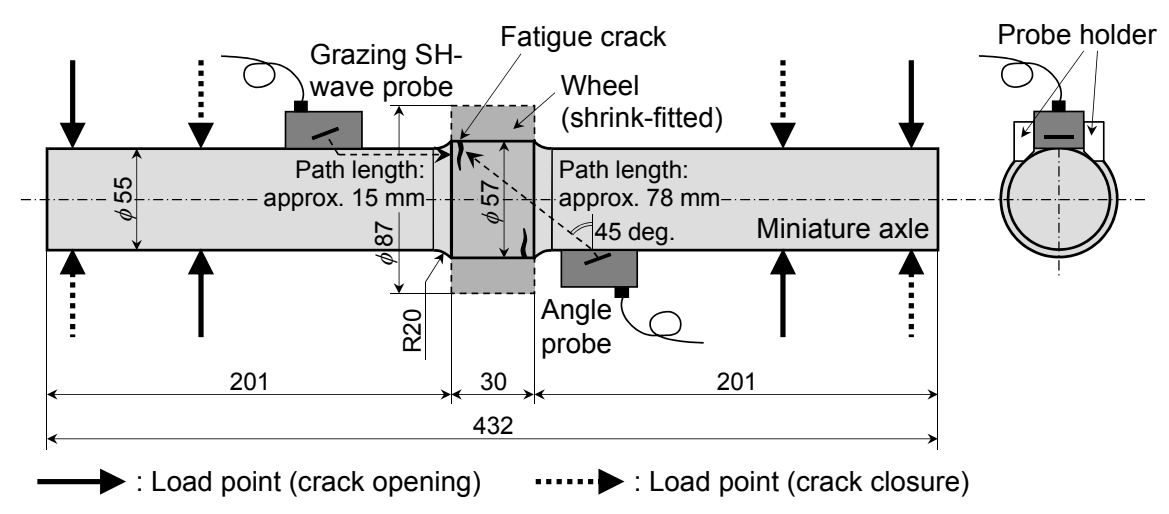

Figure 1. A schematic view of the test setup for a miniature wheelset.

The miniature axle and wheel were manufactured from a full-sized axle and wheel for railway vehicles by machining them. The materials used for the axle (SFA 60A [18]) and the wheel (SSW-QS [19]) are the carbon steel, whose chemical and mechanical properties described in JIS (Japanese Industrial Standards) are presented in Table 1. The axle material SFA 60A is close to EA1N described in EN 13261. There exists no material which is equivalent to the wheel material SSW-QS, although the tensile strength is close to ER7 in EN 13262 and the carbon content is close to Class B in AAR (Association of American Railroads). 
Table 1. Chemical and mechanical properties of the materials.

(a) Chemical properties

\begin{tabular}{|c|c|c|c|c|c|}
\hline & $\mathrm{C}$ & $\mathrm{Si}$ & $\mathrm{Mn}$ & $\mathrm{P}$ & $\mathrm{S}$ \\
\hline $\begin{array}{c}\text { SFA 60A } \\
\text { (for axle) }\end{array}$ & $0.35-0.48$ & $0.15-0.40$ & $0.40-0.85$ & $\leq 0.035$ & $\leq 0.040$ \\
\hline $\begin{array}{c}\text { SSW-QS } \\
\text { (for wheel) }\end{array}$ & $0.60-0.75$ & $0.15-0.35$ & $0.50-0.90$ & $\leq 0.045$ & $\leq 0.050$ \\
\hline
\end{tabular}

(b) Mechanical properties

\begin{tabular}{|c|c|c|c|c|c|}
\hline & $\begin{array}{c}\text { Yield point } \\
\sigma_{\mathrm{S}}(\mathrm{MPa})\end{array}$ & $\begin{array}{c}\text { Tensile strength } \\
\sigma_{\mathrm{B}}(\mathrm{MPa})\end{array}$ & $\begin{array}{c}\text { Elongation } \\
\delta(\%)\end{array}$ & $\begin{array}{c}\text { Reduction in area } \\
\varphi(\%)\end{array}$ & $\begin{array}{c}\text { Sharpy absorbed energy } \\
E(\mathrm{~J})\end{array}$ \\
\hline $\begin{array}{c}\text { SFA 60A } \\
\text { (for axle) }\end{array}$ & $\geq 295$ & $\geq 590$ & $\geq 20$ & $\geq 30$ & $\geq 31$ \\
\cline { 2 - 6 } & $\begin{array}{c}\text { Tensile strength } \\
\sigma_{\mathrm{B}}(\mathrm{MPa})\end{array}$ & $\begin{array}{c}\text { Hardness } H_{\mathrm{B}} \\
(\text { Counter-flange rim face) }\end{array}$ & $\begin{array}{c}\text { Hardness } H_{\mathrm{S}} \\
(\text { Center of tread) }\end{array}$ \\
\cline { 2 - 6 } & $\begin{array}{c}\text { SSW-QS } \\
\text { (for wheel) }\end{array}$ & $\geq 770$ & $246-307 \mathrm{HB}$ & $37-45 \mathrm{HS}$ \\
\hline
\end{tabular}

\subsection{Development of fatigue cracks}

A schematic view of the test setup is also shown in Figure 1. To develop fatigue cracks on the surface of the wheel seat, a four-point rotating bending fatigue test machine was used. The nominal stress amplitude at the wheel seat was $165 \mathrm{MPa}$ and the rotating speed was $400 \mathrm{rpm}$. To make sure that fatigue cracks were initiated at the wheel seat, the grip section, which was an alternative site for the crack initiation, was reinforced by a hydrostatical ball point tool. Whether a fatigue crack had been developed or not was checked by using a grazing SH-wave probe during the fatigue test in every $5 \times 10^{5}$ cycles of rotation. The total number of rotation cycles was $2 \times 10^{6}$. As a result, two fatigue cracks were initiated by the effect of the fretting at the axle-wheel interface, and developed on the surface of the wheel seat as ordinary fatigue cracks under bending. Their presence was also clarified by the destructive test performed after finishing all the ultrasonic test menus.

\subsection{Ultrasonic testing}

Two types of special ultrasonic probes manufactured by Japan Probe Co., Ltd. were employed, namely, shear-wave angle probes with the angle of refraction of 45 degrees, and grazing SH-wave probes. Probes with different nominal frequencies were used for each type, i.e. 2 and $5 \mathrm{MHz}$ for angle probes and 2, 3 and $5 \mathrm{MHz}$ for grazing SH-wave probes. The transducer sizes of these probes were all $5 \mathrm{~mm} \times 5 \mathrm{~mm}$. Each probe was attached to the curved surface of the test piece by aid of a special holder to fix its orientation, as shown in the side view of Figure 1, and the ultrasound was transmitted through the flat surface of the probe in a contact mode with acoustic couplant.

Two fatigue cracks as described above were examined in ultrasonic testing. When angle probes were used, the echo height was measured at the position where the path length was approximately $78 \mathrm{~mm}$ and the echo height was at the maximum. This path length can be readily obtained as $\left(r_{1}+r_{2}\right) / \cos 45^{\circ}$, where $r_{1}$ and $r_{2}$ are the outer radii of the axle body and the wheel seat, respectively. When grazing SH-wave probes were used, the echo height was measured at the position where the path length was approximately $15 \mathrm{~mm}$. The same four-point rotating bending fatigue test machine employed to develop fatigue cracks was used to 
apply the crack opening and closure stresses at the time of an ultrasonic testing. In performing ultrasonic measurements for each crack, the axle was positioned in the test machine so that the crack to be examined was located farthest from the neutral plane and subjected to the maximum stress amplitude.

The measurements were performed in the following procedure. At first, we carried out the ultrasonic measurements with a wheel being fitted as a wheelset. The applied load cycle varied the nominal stress at the wheel seat from 0 up to $+165 \mathrm{MPa}$, then reversely down to $-165 \mathrm{MPa}$, and back to 0 . The echo height was measured in every increment of $15 \mathrm{MPa}$. The measurements were performed after two times of pre-loading to attain the stabilized data at a fatigue crack. Next, we removed the wheel by cutting it, and performed the same menus of ultrasonic testing for the axle without a wheel. After all ultrasonic measurements, the fatigue cracks were opened destructively to obtain the actual crack depths.

An ultrasonic flaw detector AD-3212 (A\&D Co., Ltd.) was used for the measurement. The frequency range was $0.5-10 \mathrm{MHz}$ and the maximum amplifier gain was $84 \mathrm{~dB}$. The pulser was the square wave: the pulse voltage was $200 \mathrm{~V}$, the damping was $180 \Omega$ and the pulse width was $250 \mathrm{~ns}$ for $2 \mathrm{MHz}$ probes and $100 \mathrm{~ns}$ for 3 and $5 \mathrm{MHz}$ probes. The low-pass filter was set as $2 \mathrm{MHz}$ when we used $2 \mathrm{MHz}$ probes, and as $5 \mathrm{MHz}$ when we used 3 or $5 \mathrm{MHz}$ probes. In order to normalize the echo height, the reflections at the axle edge, $h_{\mathrm{e}(\text { angle })}$ and $h_{\mathrm{e}(\mathrm{SH})}$, were measured for the same test piece as shown in Figure 2. The measured echo height $h$ was divided by $h_{\mathrm{e}}$ to obtain the normalized echo height.

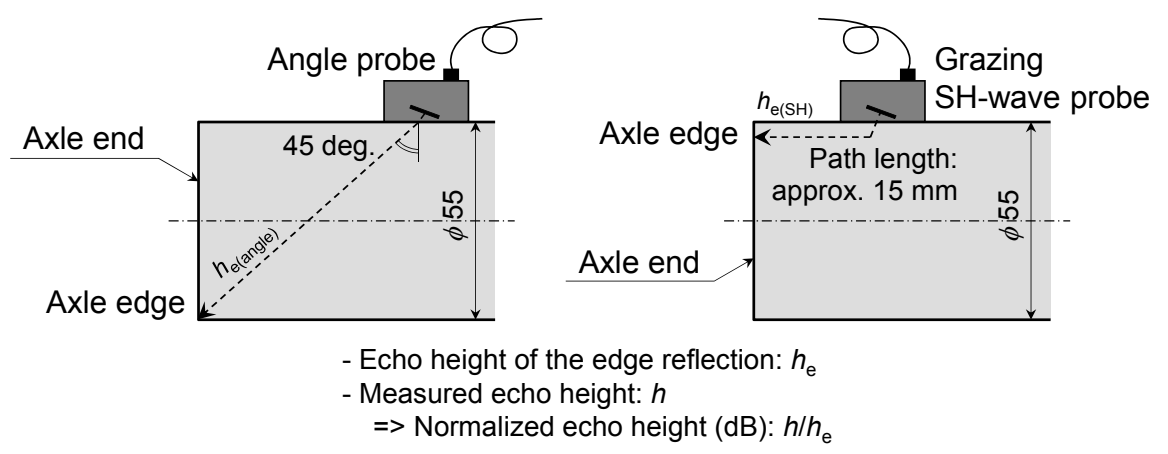

(a) Measurement with an angle probe

(b) Measurement with a grazing $\mathrm{SH}-$ wave probe

Figure 2. Measurements of the edge reflection for the normalization of the echo height.

\subsection{Estimation of crack depth}

As the cracks at the wheel seat were expected to have developed as ordinary fatigue cracks, we attempted to examine the possibility of sizing their depths in comparison to artificial flaws. Six artificial flaws were machined by the electric discharge machining (EDM) on a miniature axle test piece shown in Figure 3, which had almost the same dimensions as those of the axle in a miniature wheelset shown in Figure 1, but did not have a wheel fitted on it. The target depths for these flaws were $0.15,0.3,0.6,1,2$ and $3 \mathrm{~mm}$, respectively.

We carried out the ultrasonic testing of these artificial flaws using the same probes, and constructed the calibration curves between the flaw depth and the echo height. These calibration curves were used to estimate the depths of fatigue cracks from the echo height obtained. We then compared the estimated 
depths to the actual depths of the fatigue cracks by the destructive examination.

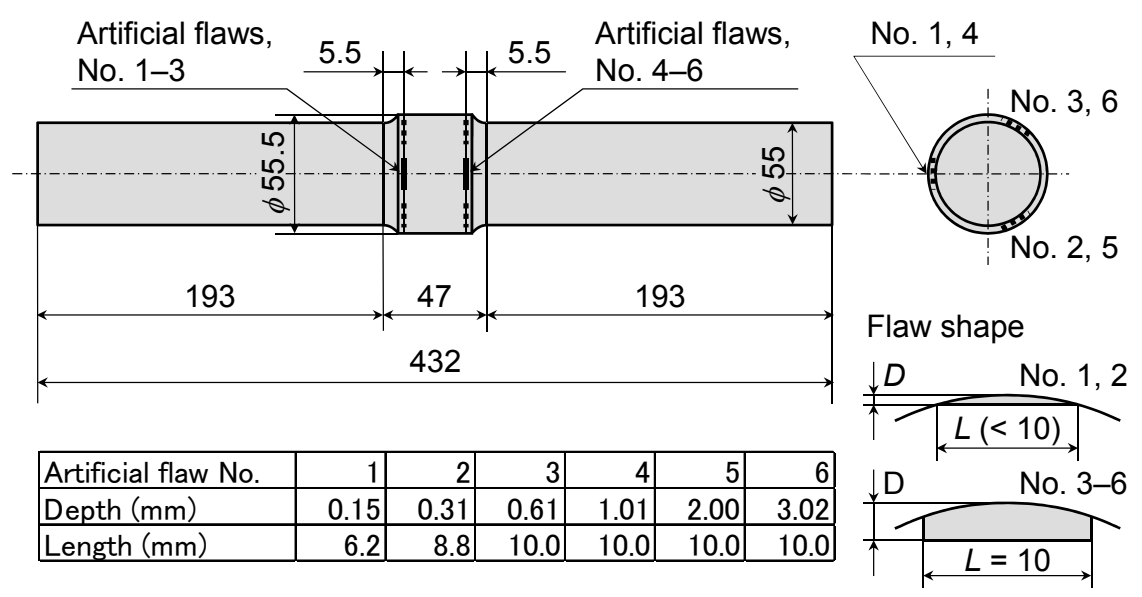

Figure 3. A drawing of a miniature axle with artificial flaws in different depths.

\section{Results and discussions}

\subsection{Actual features of fatigue cracks}

Before discussing the ultrasonic test results, the features of the two fatigue cracks which lied on the axle are noted. Figure 4 shows the faces of two fatigue cracks which were forcibly opened after finishing all the ultrasonic test menus. The deeper crack shown in Figure 4(a) is referred to as the fatigue crack No. 1, whose actual depth was $3.5 \mathrm{~mm}$, and the shallower crack in Figure 4(b) is the fatigue crack No. 2, whose actual depth was $1.3 \mathrm{~mm}$. The distance of the fatigue cracks from the edge of the wheel seat was around 0.7 $\mathrm{mm}$.

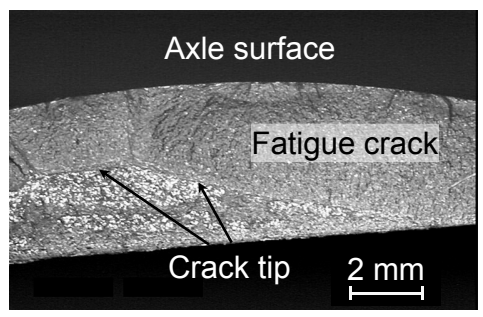

(a) Fatigue crack No. 1 Depth: $3.5 \mathrm{~mm}$

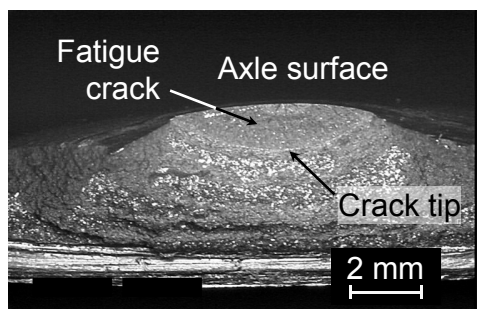

(b) Fatigue crack No. 2 Depth: $1.3 \mathrm{~mm}$

Figure 4. The faces of two fatigue cracks.

\subsection{Recorded waveforms}

The ultrasonic waveforms as to the crack No. 1 recorded when the nominal stress at the wheel seat was -165 and $+165 \mathrm{MPa}$ are shown in Figure 5, when two types of probes with the nominal frequencies of 2 and $5 \mathrm{MHz}$ were used (the waveforms with the $3 \mathrm{MHz}$ grazing $\mathrm{SH}$-wave probe are omitted here). The arrow in each waveform indicates the estimated position of an echo reflected at this crack. To ease the visualization, the displayed echo is adjusted to the height of 80 percent against the full scale of the vertical axis, except in the situation where the echo signal was so small and noisy signals were dominant. The shape 
of the test piece, the wave propagation paths and typical waveforms are shown in Figure 6 for an angle probe and in Figure 7 for a grazing SH-wave probe.

In Figure 5(a) and (b), showing the results obtained by angle probes, it is noted that the crack echo is associated with another clear echo in the waveforms of the wheelset at a path length of approximately 92 $\mathrm{mm}$, which is not present in the waveforms of the axle only. This echo is considered to be a reflection from the outer edge of the wheel through the interface of the axle and wheel, which is described as (2) in Figure 6. The path length $92 \mathrm{~mm}$ corresponds to the geometric distance which is calculated from this figure. The presence of this echo indicates that the transmission coefficient at the axle-wheel interface would be relatively high. In addition, since the shape of the outer edge of the wheel itself is, in a sense, considered to be a large flaw, it is expected that the reflection from the edge is somewhat larger than that from the cracks even after the ultrasound travelled forward and backward through the axle-wheel interface.

In Figure 5(c) and (d) for grazing SH-wave probes, it is noted that the crack echo is associated with another clear echo at a path length of approximately $44 \mathrm{~mm}$. This echo is considered to be a reflection from the opposite edge of the wheel seat. When the tensile stress was applied, the height of this echo decreased since the ultrasound reflected at the crack, that is, the crack opened by the tensile stress blocked the ultrasound from going through it and arriving at the opposite edge. This mechanism is explained in Figure 7.

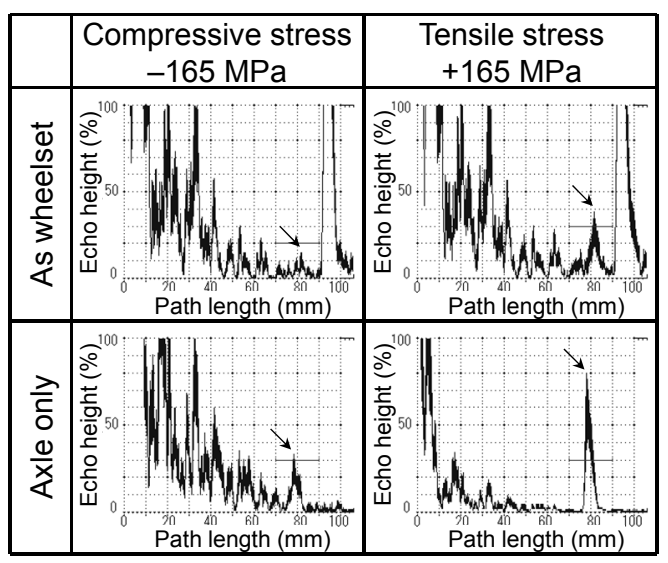

(a) $2 \mathrm{MHz}$ angle probe

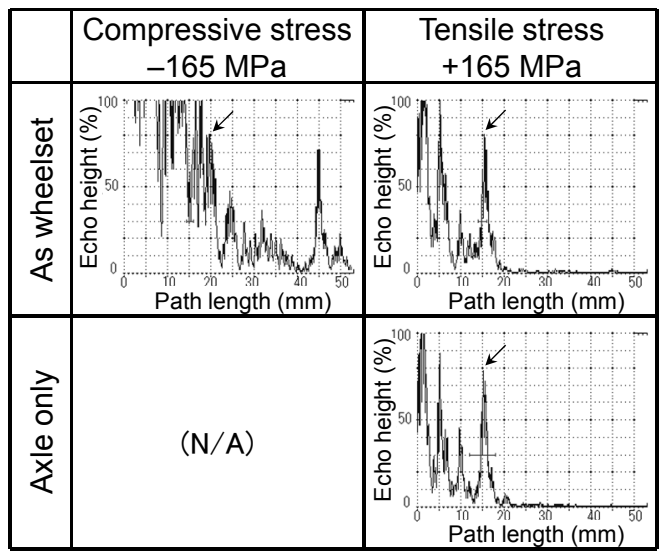

(c) $2 \mathrm{MHz}$ grazing SH-wave probe

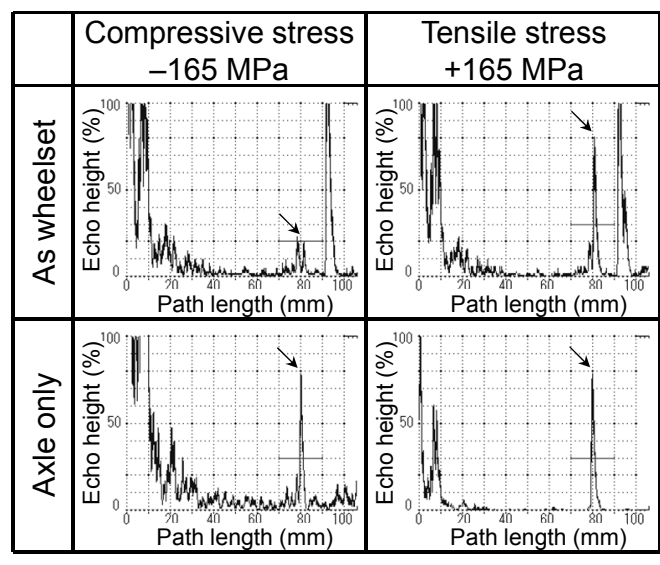

(b) $5 \mathrm{MHz}$ angle probe

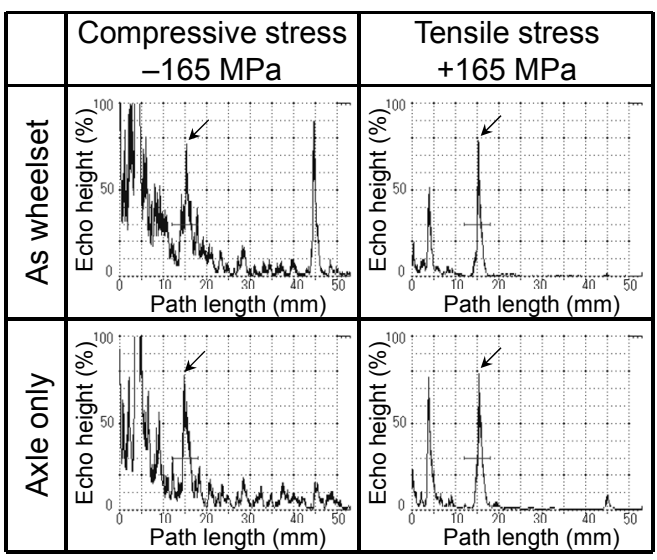

(d) $5 \mathrm{MHz}$ grazing SH-wave probe

Figure 5. The waveforms as to the crack No. 1. 


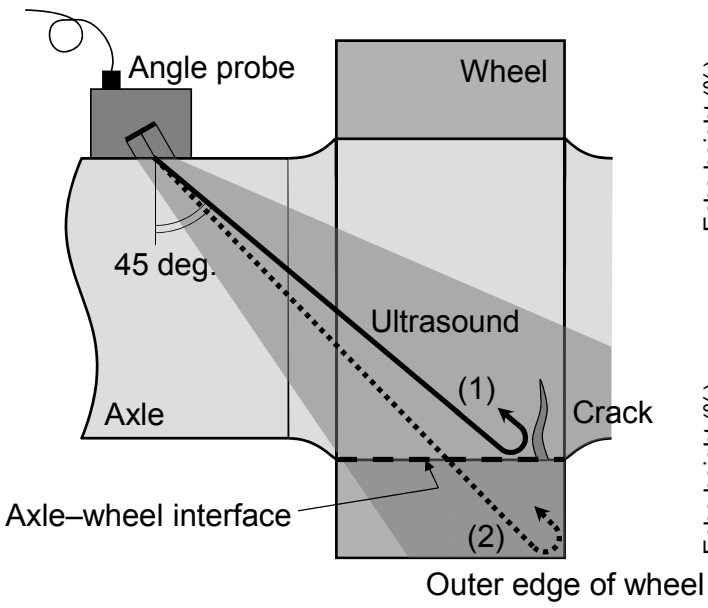

(2)

(1) Reflection from a crack

(2) Reflection from the outer edge of the wheel

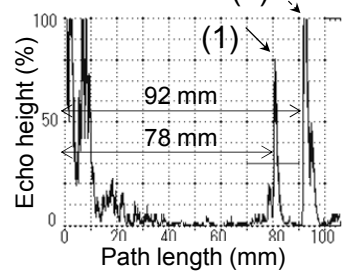

(a) As wheelset

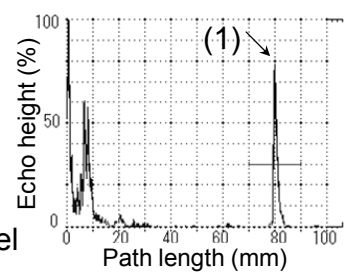

(b) Axle only

through the axle-wheel interface

Figure 6. The shape of the test piece, the wave propagation paths and typical waveforms for an angle probe.

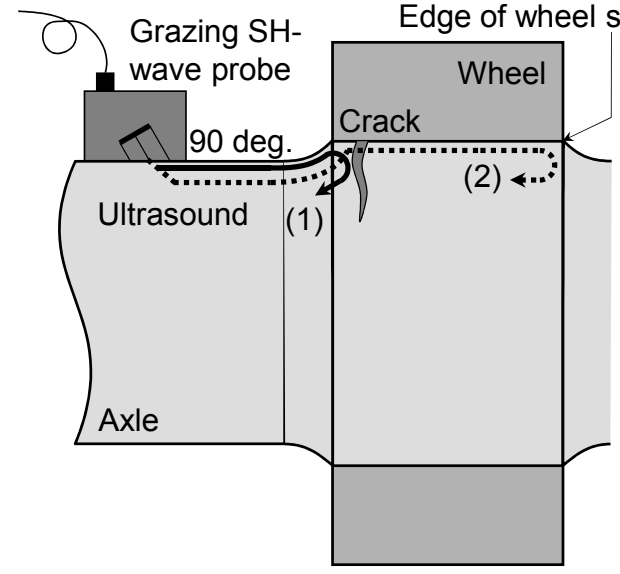

(1) Reflection from a crack

(2) Reflection from the opposite edge of the wheel seat through the crack

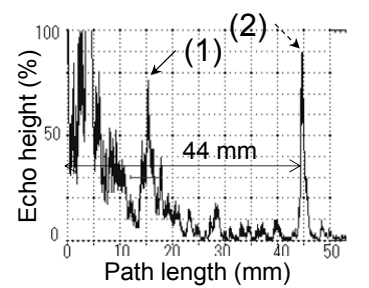

(a) With compressive stress or no stress

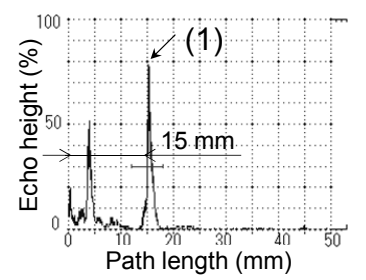

(b) With tensile stress

Figure 7. The shape of the test piece, the wave propagation paths and typical waveforms for a grazing SH-wave probe.

In Figure 5(a) to (d), remarkable effects of the bending load on the echo signals can be observed when the axle is with or without the wheel. For example, from the left-top waveform in Figure 5(a) obtained by the $2 \mathrm{MHz}$ angle probe, it is difficult to identify the crack No. 1 if it exists under the wheel (as a wheelset) and the stress condition is in compression. Figure 5(b) shows the waveforms tested by the $5 \mathrm{MHz}$ angle probe. From the left-top waveform, it is also difficult to identify this crack, the situation being basically similar to that with the $2 \mathrm{MHz}$ angle probe. The waveforms except the left-top, however, are very clear compared to those obtained by the $2 \mathrm{MHz}$ angle probe.

Figure 5(c) shows the waveforms tested by the $2 \mathrm{MHz}$ grazing SH-wave probe. From these waveforms, it is also difficult to identify the crack No. 1 unless sufficient tensile stress is applied, since the 
signal-to-noise ratio is not high enough. Figure 5(d) shows the waveforms tested by the $5 \mathrm{MHz}$ grazing SH-wave probe. As compared to Figure 5(c), the left-top waveform in Figure 5(d) is clearer and the signal-to-noise ratio is higher to some extent. This result suggests some superiority in using this probe for the flaw echo detection when a fatigue crack at the wheel seat is closed under a compressive stress condition

Similar tendency as described above was observed when we tested on the crack No. 2, although the signal-to-noise ratios were somewhat more deteriorated than those obtained for the crack No. 1.

\subsection{Echo heights}

The echo heights of the fatigue cracks No. 1 and 2 are plotted in Figures 8 and 9, respectively, against the nominal stress at the wheel seat. The vertical axis in each graph corresponds to the normalized echo height in $\mathrm{dB}$ in terms of the above-mentioned edge reflection $h_{\mathrm{e}}$, and the horizontal axis is the nominal stress applied to the wheel seat. In each figure, the left two graphs show the results when we used angle probes, and the right two graphs show those when we used grazing SH-wave probes. The top two graphs show the results when the axle was fitted with a wheel as a wheelset, and the bottom two graphs show those after a wheel was removed.

From Figure 8 for the echo height of the crack No. 1, one can readily find that there is a hysteresis in the echo-height variation according to the load history. The curve when the nominal stress was increased was lower than that when the nominal stress was decreased. This phenomenon could be explained by the contact interaction between the inner surface of a wheel and the (outer) surface of an axle as well as the interaction between the opposite faces of a crack, which was previously observed for contacting interfaces between solid bodies [20-24].

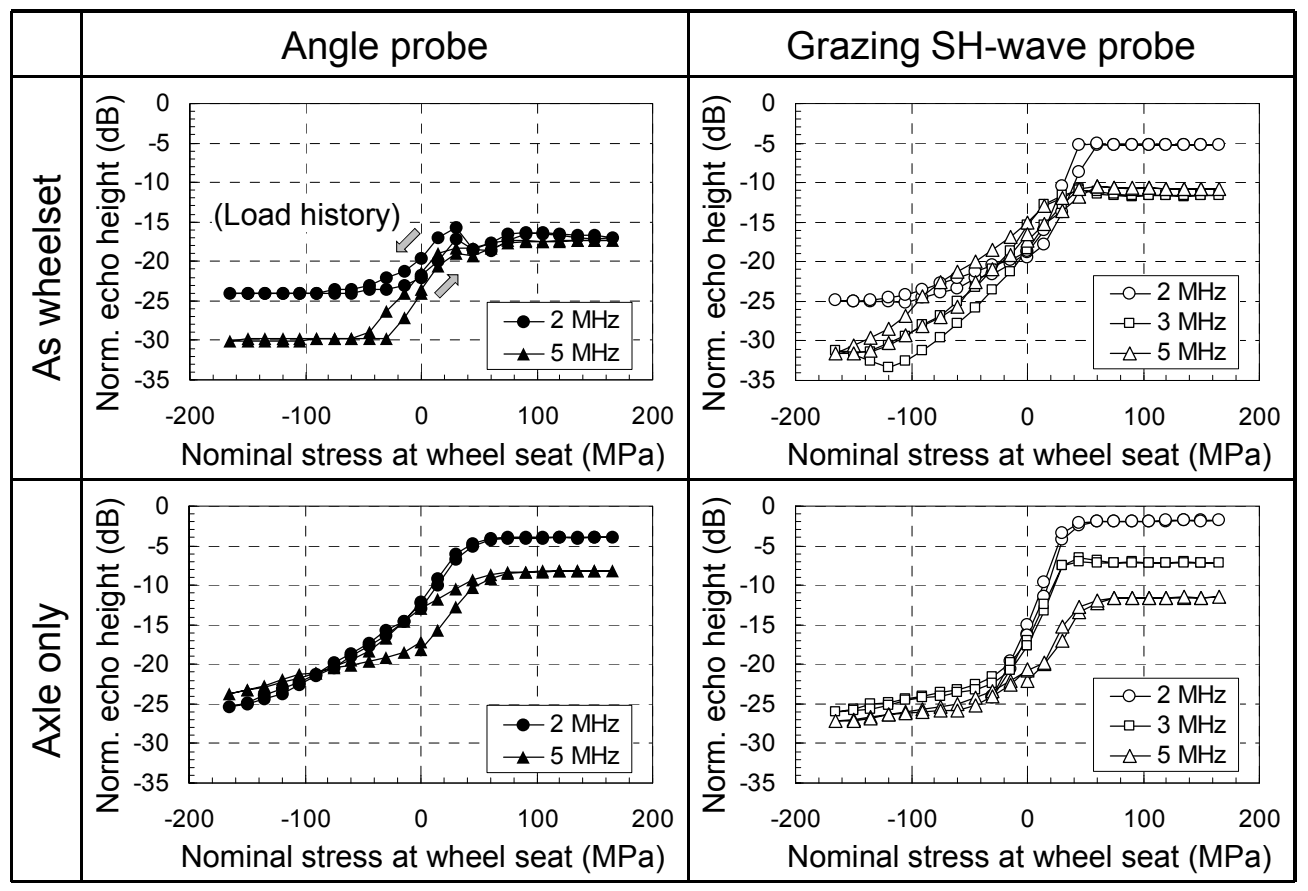

Figure 8. The echo-height variation in the crack No. 1. 


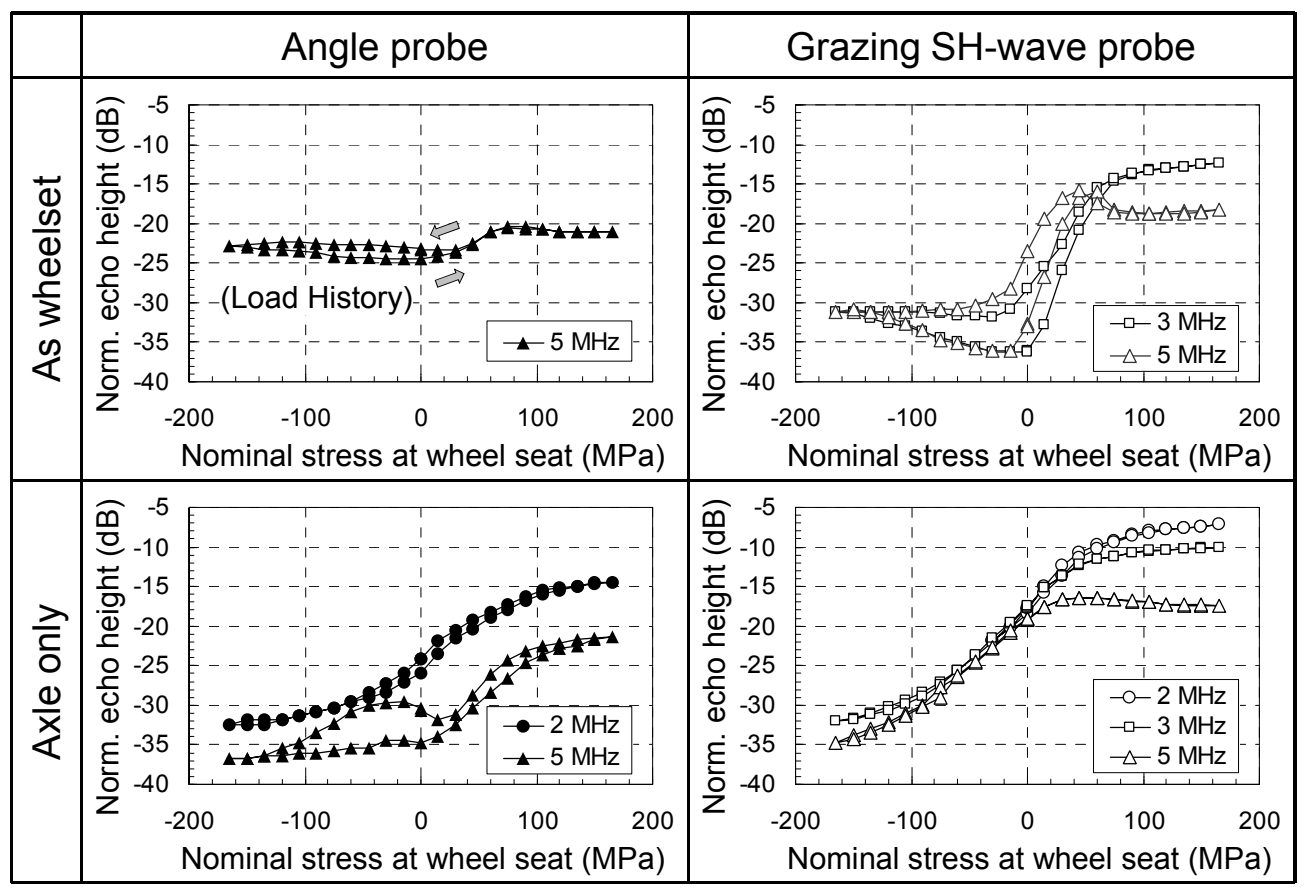

Figure 9. The echo-height variation in the crack No. 2.

In addition, the echo height in Figure 8 saturated when the tensile stress was higher than approximately $50 \mathrm{MPa}$. This fact indicates that the state of a fatigue crack with a relatively large depth (3.5 $\mathrm{mm}$ for the crack No. 1) approaches that of an open flaw when the crack is subjected to sufficiently high tensile stresses. Saka and Akanda [13] reported that the crack opening stress which made a crack ultrasonically open was approximately $70 \mathrm{MPa}$ when they measured a fatigue crack in a stainless-steel test piece by using a probe with the nominal frequency of $5 \mathrm{MHz}$ and a shear-wave refraction angle of 50 degrees, which was a similar tendency to our result.

When the echo height was measured with angle probes, the normalized echo heights with the $5 \mathrm{MHz}$ probe were comparable to or lower than those with the $2 \mathrm{MHz}$ probe. Moreover, when grazing SH-wave probes were used, the normalized echo heights were apparently lower when the nominal frequency was higher: the reason for this is discussed later.

Next, we explain the results as to the crack No. 2 shown in Figure 9. In the top two graphs in this figure, the plots by $2 \mathrm{MHz}$ probes are not shown since it was not possible to identify flaw echoes with these probes. For the crack No. 2, there is also a hysteresis according to the load history. The echo height did not show saturation even when high tensile stress was applied. The echo height increased gradually according to the increase in the tensile stress, which was a different tendency from that in the crack No. 1 . This fact indicates that it was difficult to let this small crack completely open under the tensile stress condition from the viewpoint of the ultrasound transmission.

\subsection{Discussion on the effect of tensile stress on echo heights}

The results in Figures 8 and 9 have revealed that the tensile stress acts to open the crack and increase its echo height. To quantify this increase, the ratio of the echo height under the maximum tensile stress to 
that in the no-load condition was computed in each case as shown in $\mathrm{dB}$ scale in Table 2 for the crack No. 1. When the test piece was fitted with a wheel as a wheelset, the average value of the increase was $7.7 \mathrm{~dB}$, and when without a wheel, i.e. "axle only," the value was $10.9 \mathrm{~dB}$. The dispersion of the increase values was wider when the test piece was fitted with a wheel. The reason for this dispersion is considered to be due to the variation of the contact condition around the crack in each measurement, since the crack opening is interfered by the contact pressure by the wheel and the friction generated in consequence.

Table 2. The echo-height increase in the crack No. 1.

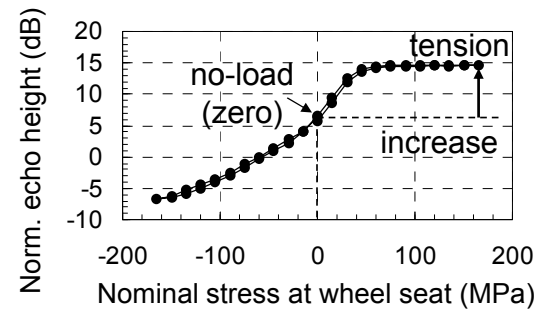

(a) With wheel (as wheelset)

\begin{tabular}{|c|c|c|c|}
\hline $\begin{array}{c}\text { Crack } \\
\text { No. }\end{array}$ & $\begin{array}{l}\text { Probe } \\
\text { type }\end{array}$ & $\begin{array}{l}\text { Freq. } \\
\text { (MHz) }\end{array}$ & $\begin{array}{l}\text { Increase in } \\
\text { echo height } \\
\text { (dB) }\end{array}$ \\
\hline \multirow{5}{*}{1} & \multirow{2}{*}{ Angle } & 2 & 4.7 \\
\hline & & 5 & 6.2 \\
\hline & \multirow{3}{*}{$\begin{array}{c}\text { Grazing } \\
\mathrm{SH}\end{array}$} & 2 & 14.2 \\
\hline & & 3 & 6.8 \\
\hline & & 5 & 6.6 \\
\hline
\end{tabular}

Average value of increase: $7.7 \mathrm{~dB}$

(b) Without wheel (axle only)

\begin{tabular}{|c|c|c|r|}
\hline $\begin{array}{c}\text { Crack } \\
\text { No. }\end{array}$ & $\begin{array}{c}\text { Probe } \\
\text { type }\end{array}$ & $\begin{array}{c}\text { Freq. } \\
(\mathrm{MHz})\end{array}$ & $\begin{array}{c}\text { Increase in } \\
\text { echo height } \\
(\mathrm{dB})\end{array}$ \\
\hline \multirow{4}{*}{1} & Angle & 2 & 9.0 \\
\cline { 3 - 4 } & & 5 & 10.0 \\
\cline { 2 - 4 } & $\begin{array}{c}\text { Grazing } \\
\text { SH }\end{array}$ & 2 & 14.4 \\
\cline { 3 - 4 } & & 5 & 10.4 \\
\hline
\end{tabular}

Average value of increase: $10.9 \mathrm{~dB}$

The reason why the echo-height increase was relatively small when a wheel was fitted on the axle can be explained as follows, by examining the ultrasound transmission and reflection at the crack as well as the axle-wheel interface. The attention is now given to the case with angle probes, although a similar discussion may be applicable to the case with grazing SH-wave probes. A schematic illustration of the angle beam reflection is given in Figure 10. It is first noted that the ultrasound is partially transmitted into the wheel (as represented by $T_{1}$ in the drawing), in contrast to the situation when the axle surface is traction-free as shown in Figure 10(a) $\left(\mathrm{T}_{1} \approx 0\right)$. In the bending-free state of the wheelset as shown in Figure 10 (b), the central part of the opposite crack faces tends to be expanded (opened) by the effect of the contact pressure by the wheel, although the surface-breaking part and the tip of the crack faces could remain in contact with each other. Then, when the tensile stress is applied by the bending load, the friction of the axle-wheel interface may resist against the opening of the crack faces as shown in Figure 10(c) (it is also likely that the contact pressure at the axle-wheel interface changes to a certain order). It is considered that this relatively complicated effect of the axle-wheel contact yielded, as a whole, the reduction in the echo-height increase. 


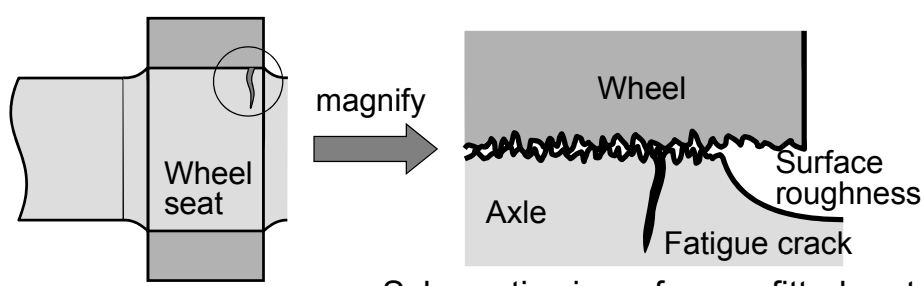

Schematic view of press-fitted part

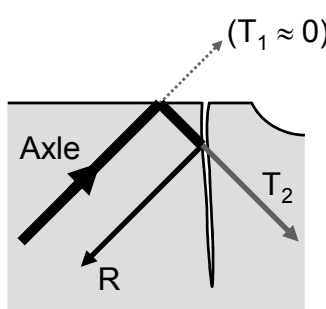

(a) Axle only

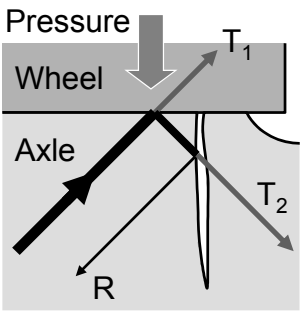

(b) As wheelset

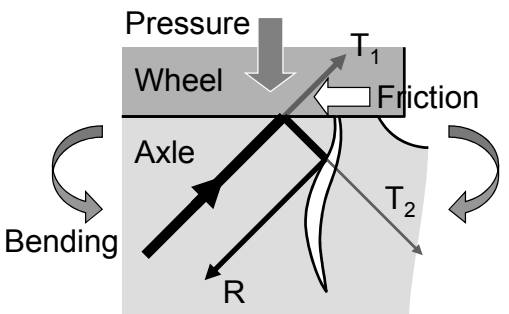

(c) As wheelset (with bending load)

Figure 10. The behaviour of the ultrasound around a fatigue crack at the wheel seat.

\subsection{Results of crack depth estimation}

We measured the echo heights of 6 artificial flaws on the test piece in Figure 3 without applying bending load, and constructed the calibration curves for angle probes and grazing SH-wave probes. Figure 11 shows the calibration curves for the miniature axle without a wheel. We estimated the depth of two fatigue cracks by applying their echo height to this calibration curve. The crack depth estimation was performed with the data of the fatigue cracks acquired when they were under the maximum tensile stress condition.

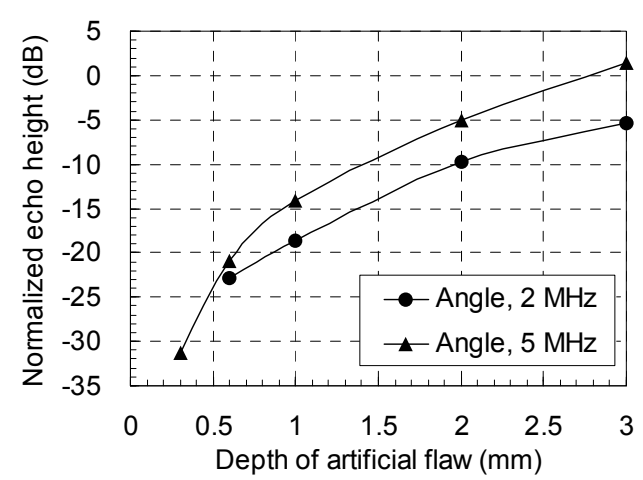

(a) Angle probe

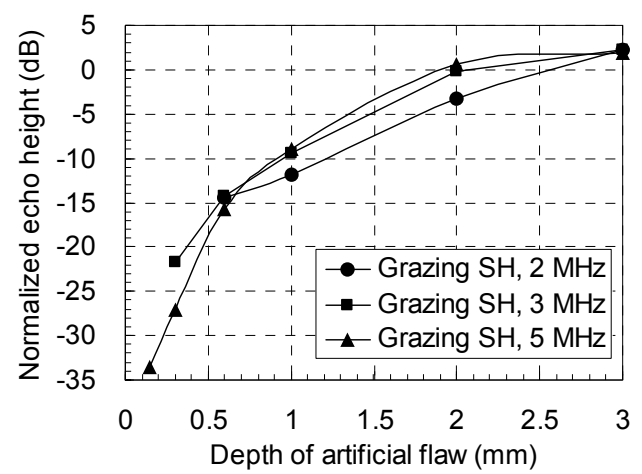

(b) Grazing SH-wave probe

Figure 11. Calibration curves for the crack depth estimation.

Table 3 shows the actual depths of cracks by the destructive examination and the estimated depths obtained by the ultrasonic testing. When we used the probes with the nominal frequency of $2 \mathrm{MHz}$, as shown in Table 3(a), the actual and estimated values of the crack depths were relatively close to each other when a wheel was not fitted above the cracks. For example, the estimated depth of the crack No. 1 was deeper than $3.0 \mathrm{~mm}$ by using an angle probe and $2.2 \mathrm{~mm}$ by using a grazing SH-wave probe, respectively, 
which were relatively close to the actual depth, i.e. $3.5 \mathrm{~mm}$.

When the nominal frequency of a probe was $5 \mathrm{MHz}$, the depths of the fatigue cracks were underestimated to the actual depths. As it will be suggested in the following section, one reason for this might be that for higher frequency, the echo height can be influenced more severely by the local inclination and roughness of the fatigue crack, which reduces the detected echo height and thus becomes a source of underestimation of the crack depth when the echo height is applied to the calibration curve for artificial flaws with more ideal surfaces.

Moreover, when we focus on the left two columns in the "Estimated depth" column in Table 3(a) and (b), representing the results for the case when a wheel was fitted above the cracks, the estimated depths appear to be less than half of the actual depths. As discussed in the previous section, this is considered to be due to the partial transmission of the ultrasound into the wheel as well as due to the resistance to the crack opening by the fitted wheel, which yielded the underestimation when the calibration curves for the axle without a wheel were used. This effect should be taken care of properly, when we estimate the size of cracks on the fitting part.

Table 3. Actual and estimated depths of fatigue cracks.

(a) Nominal frequency of probes: $2 \mathrm{MHz}$

\begin{tabular}{|c|c|c|c|c|c|}
\hline \multirow{2}{*}{$\begin{array}{c}\text { Crack } \\
\text { No. }\end{array}$} & \multirow{2}{*}{$\begin{array}{c}\text { Actual } \\
\text { depth } \\
(\mathrm{mm})\end{array}$} & \multicolumn{4}{|c|}{ Estimated depth (mm) } \\
\cline { 3 - 6 } & & With wheel (as wheelset) & Without wheel (axle only) \\
\cline { 3 - 6 } & & $\begin{array}{c}\text { Grazing } \\
\text { probe }\end{array}$ & $\begin{array}{c}\text { SH-wave } \\
\text { probe }\end{array}$ & $\begin{array}{c}\text { Angle } \\
\text { probe }\end{array}$ & $\begin{array}{c}\text { Grazing } \\
\text { SH-wave } \\
\text { probe }\end{array}$ \\
\hline 1 & 3.5 & 1.2 & 1.8 & $>3.0$ & 2.2 \\
\hline 2 & 1.3 & N/A & N/A & 1.4 & 1.5 \\
\hline
\end{tabular}

(b) Nominal frequency of probes: $5 \mathrm{MHz}$

\begin{tabular}{|c|c|c|c|c|c|}
\hline \multirow{2}{*}{$\begin{array}{c}\text { Crack } \\
\text { No. }\end{array}$} & Actual & \multicolumn{4}{|c|}{$\begin{array}{c}\text { Estimated depth }(\mathrm{mm}) \\
\text { depth }\end{array}$} \\
\cline { 3 - 6 } & $(\mathrm{mm})$ & With wheel (as wheelset) & Without wheel (axle only) \\
\cline { 3 - 6 } & probe & $\begin{array}{c}\text { Grazing } \\
\text { SH-wave } \\
\text { probe }\end{array}$ & $\begin{array}{c}\text { Angle } \\
\text { probe }\end{array}$ & $\begin{array}{c}\text { Grazing } \\
\text { SH-wave } \\
\text { probe }\end{array}$ \\
\hline 1 & 3.5 & 0.8 & 0.8 & 1.6 & 0.8 \\
\hline 2 & 1.3 & 0.6 & 0.5 & 0.6 & 0.6 \\
\hline
\end{tabular}

\subsection{Remark on the influence of the nominal frequency}

In the Section 3.3, it was noted for both angle probes and grazing SH-wave probes that the probes with higher nominal frequency gave lower or comparable echo heights from a crack compared to those with lower frequency. This fact led to the underestimation of the crack depth as discussed in the previous section.

Usually, the directivity angle of the ultrasonic beam is proportional to the wavelength [25], namely, inversely proportional to the frequency. Therefore, considering the ratio of the crack length to the beam-spread length in the circumferential direction, it is naturally expected that higher frequency would 
give higher echo heights.

In the present experiment, however, the probes were attached to the curved surface of the axle in the manner of a line contact. As shown in Figure 12, the ultrasonic beam is radiated through the effective transducer width $D_{\text {eff }}$ which is smaller than the nominal width $D$, as well as the area filled by the acoustic couplant. In the case of higher frequency, the beam is essentially radiated only through a smaller effective width determined by the interaction between the wave length and the local thickness of acoustic couplant [26], which tends to make its circumferential beam-spread length larger. In spite of this effect, Figure 11 shows that for artificial flaws in the calibration test piece the probes with higher frequency still gave higher echo heights. It is noted in passing that the effect of a curved wedge to fit the probe to the axle surface would be limited for a relatively small radius of the miniature axle used here. This is explained by the fact that the refraction angle of the ultrasound in the circumferential direction will become higher as the incident point of the ultrasound becomes farther from the centre of the transducer. Therefore, the concept of the effective transducer width $D_{\text {eff }}$ as mentioned above will remain more or less valid even if such wedges are used.

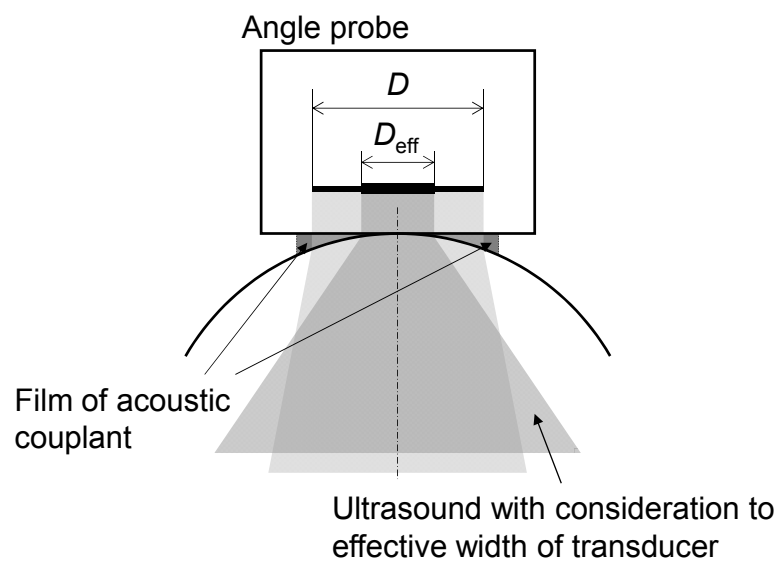

Figure 12. A schematic view of the ultrasound propagation by a probe with a flat contact surface.

In the case of fatigue cracks, however, it should be taken into account that crack faces are often locally inclined and rough, especially for fretting fatigue cracks [27, 28]. The fatigue cracks in our experiment are too deep to be referred to as the "fretting" fatigue cracks, since the depth of their fretting-dominated region is considered to be several hundred micrometers. Nevertheless, the ultrasonic wave with higher frequency would be much more affected by the local inclination and roughness of the crack, and consequently more attenuated or scattered into a wider direction when it is reflected by the crack. This may explain the observed fact that the probes with higher nominal frequency gave lower or comparable echo heights of the crack compared to those with lower frequency.

\subsection{Application of the test results to the full-sized wheelsets}

In the case of applying the test results obtained by the miniature wheelset to the full-sized ones, it should be noted that the longer path length of the full-sized wheelset makes the echo heights smaller. 
However, the results of the miniature wheelset were obtained for the cracks which existed in the region outside the near field of the ultrasound. Therefore, it is considered that the qualitative tendency will be similar in both cases of the miniature and full-sized wheelsets.

In the full-sized wheelset, the bending stress is usually given by the static load of the car weight, which is around $50 \mathrm{MPa}$ at the maximum. This is much smaller than the stress level applied in this study, i.e. $165 \mathrm{MPa}$. However, the stress level of $50 \mathrm{MPa}$, which was found to sufficiently open a crack in the miniature wheelset, will be also attainable in the full-sized wheelsets. The present results have revealed that applying the tensile stress to the wheelsets is advantageous to the crack detection. Therefore, in the case when a full-sized wheelset is inspected after dismantled from the car but still fitted with wheels, for example, the inspection accuracy is expected to increase if the axle is inspected ultrasonically by rotating it to keep the tensile stress being always applied to the inspection site. When the axles are inspected in a state of a train, the present results would suggest that the threshold level for the crack detection in the circumferential direction should be adjusted based on the echo-height variation caused by the tensile/compressive stress ranging -50 to $50 \mathrm{MPa}$.

The grazing SH-wave probe was found to be effective in the crack detection at the wheel seat of a miniature axle. The miniature axle used here had a transition from the wheel seat to the axle body with a radius of $20 \mathrm{~mm}$ as shown in Figure 1. This radius is smaller than those of the full-sized axles. Since the grazing SH wave was found to pass through the transition with such a small radius, the results obtained by the miniature wheelset with the grazing SH-wave probes are expected to be applicable to the practical case with the full-sized axles.

\section{Conclusions}

We can conclude our study as follows. We measured the echo-height variation and the waveforms with the two fatigue cracks that were developed by rotating bending fatigue test at the wheel seat of a miniature wheelset test piece, when the axle was subjected to bending loads which applied compressive/tensile stresses to the cracks. The depths of the cracks were $3.5 \mathrm{~mm}$ and $1.3 \mathrm{~mm}$, respectively. There was a hysteresis in the variation of the echo height according to the load history. The state of a fatigue crack with a depth of $3.5 \mathrm{~mm}$ approached that of an open flaw when the crack was subjected to the tensile stress which was higher than approximately $50 \mathrm{MPa}$.

We quantified the echo-height increase due to the crack opening effect of the tensile stress, by comparing the data under the maximum tensile stress and the no-load condition as to the 3.5-mm-deep crack. The increase value was smaller when a wheel was fitted on the axle covering the crack, compared to the case when it was not fitted. We explained this fact by the effect of the contact conditions of the crack faces as well as the axle-wheel interface.

The crack depth estimation was also carried out based on the calibration curves between the crack depth and the echo height for artificial flaws machined on a similar axle. While $2 \mathrm{MHz}$ probes gave reasonable estimated depths when the wheel was not fitted on the axle, $5 \mathrm{MHz}$ probes gave underestimated depths due probably to the effect of the local inclination and roughness of the crack. The presence of the wheel was also a source of underestimation of the crack depth, as the echo height was reduced due to the 
ultrasound transmission into the wheel and the resistance to the crack opening by the wheel.

The normalized echo height of fatigue cracks measured with the $5 \mathrm{MHz}$ angle probe was comparable to or lower than that with the $2 \mathrm{MHz}$ angle probe. Moreover, when we used grazing SH-wave probes, the normalized echo height was apparently lower when the nominal frequency of a probe was higher. We discussed these observations in a qualitative manner by considering the beam-spread length, the line-contact nature of the probe attachment, and the local inclination and roughness of the crack.

The present study has revealed the significant influence of the contact conditions at the crack faces as well as the axle-wheel interface on the crack echo detection as well as the crack depth estimation. This should be taken into account properly when axles are inspected as wheelsets, i.e. with wheels fitted.

\section{References}

[1] H. Ishiduka, Probability of improvement in routine inspection work of Shinkansen vehicle axles, Q. Rep. Railw. Tech. Res. Inst. 40 (1999), pp. 70-73.

[2] M. Carboni and S. Beretta, Effect of probability of detection upon the definition of inspection intervals for railway axles, Proc. IMechE. Part F: J. Rail and Rapid Transit 221 (2007), pp. 409-417.

[3] S. Cantini, M. Carboni and S. Beretta, NDT reliability and inspection intervals assessment by defect tolerant approach, Proc. 16th Int. Wheelset Congr. (2010), Session 8.1.

[4] B.R. Byrne, P.C. Johnson and P.G. Farley, Ultrasonic inspection of railway axles, Ultrasonics 4 (1966), pp. 143-151.

[5] J. Grum, V. Jemec and A. Beci, Experimental system for ultrasonic testing of axle sets of diesel-engine trains, Insight 42 (2000), pp. 782-788.

[6] K. Makino, J. Yohso, H. Sakamoto and H. Ishiduka, Hollow axle ultrasonic crack detection for conventional railway vehicles, Q. Rep. Railw. Tech. Res. Inst. 46 (2005), pp. 78-84.

[7] K. Makino, J. Yohso, H. Sakamoto and H. Ishiduka, An ultrasonic flaw detector for hollow axles of meter-gauge railway cars and results of axle fatigue test, Proc. 16th Int. Wheelset Congr. (2010), Session 7.4.

[8] J. Yohso, Development of automatic ultrasonic testing equipment for general and bogie inspection of Shinkansen hollow axle, Proc. 11th Int. Wheelset Congr. (1995), Vol. 2, pp. 47-50.

[9] E. Hofmann and T. Oelschlagel, Automatisierte ultraschall-prüfanlage für radsatzwellen mit längsbohrung, Eisenbahningenieur 56-5 (2005), pp. 31-37.

[10] M.B. Marshall, R. Lewis, R.S. Dwyer-Joyce, F. Demilly and Y. Flament, Ultrasonic characterisation of wheel hub/axle interference fit pressures, Proc. 14th Int. Wheelset Congr. (2004), Paper 5.3.

[11]R. Lewis, M.B. Marshall and R.S. Dwyer-Joyce, Measurement of interface pressure in interference fits, Proc. IMechE Part C: J. Mech. Eng. Sci. 219 (2005), pp. 127-139.

[12] H. Yoneyama and H. Miharada, Comparison of echo heights between fatigue crack and EDM notch, J. High Pres. Inst. Jpn. 41 (2003), pp. 115-122 (in Japanese).

[13] M. Saka and M.A.S. Akanda, Ultrasonic measurement of the crack depth and the crack opening stress intensity factor under a no load condition, J. Nondestr. Eval. 23 (2004), pp. 49-63.

[14] M.A.S. Akanda and M. Saka, Relationship between closure stress of small fatigue crack and ultrasonic 
response, J. Nondestr. Eval. 23 (2004), pp. 37-47.

[15] S.I. Rokhlin and J.-Y. Kim, In situ ultrasonic measurement of crack closure, Int. J. Fatig. 25 (2003), pp. $51-58$.

[16] H. Ishiduka and J. Yohso, Difference between cracks and artificial flaws in ultrasonic testing ultrasonic testing performed on the smooth part of a $\phi 40 \mathrm{~mm}$ miniature axle specimen - , J. Jpn. Soc. Nondestr. Inspect. 50 (2001), pp. 719-723 (in Japanese).

[17] J. Yohso, H. Sakamoto, K. Makino and H. Ishiduka, Inspection of rolling stock axles by using the grazing SH-wave ultrasonic method, Railw. Tech. Res. Inst. Rep. 16-5 (2002), pp. 35-40 (in Japanese).

[18] Japanese Industrial Standards (JIS) E 4502-1: 2001, Axles for railway rolling stock - Quality requirements.

[19] Japanese Industrial Standards (JIS) E 5402-1: 2005, Railway rolling stock — Solid wheel — Part1 : Quality requirements.

[20] S. Biwa, A. Suzuki and N. Ohno, Evaluation of interface wave velocity, reflection coefficients and interfacial stiffnesses of contacting surfaces, Ultrasonics 43 (2005), pp. 495-502.

[21] S. Biwa, S. Hiraiwa and E. Matsumoto, Stiffness evaluation of contacting surfaces by bulk and interface waves, Ultrasonics 47 (2007), pp. 123-129.

[22] D. Liaptsis, B.W. Drinkwater and R. Thomas, The interaction of oblique incidence ultrasound with rough, partially contacting interfaces, Nondestr. Test. Eval. 21 (2006), pp. 109-121.

[23] R. Thomas, B.W. Drinkwater and D. Liaptsis, The reflection of ultrasound from partially contacting rough surfaces, J. Acoust. Soc. Am. 117 (2005), pp. 638-645.

[24] B.W. Drinkwater, R.S. Dwyer-Joyce and P. Cawley, A study of the interaction between ultrasound and a partially contacting solid-solid interface, Proc. R. Soc. Lond. A 452 (1996), pp. 2613-2628.

[25] A. Freedman, Sound field of a rectangular piston, J. Acoust. Soc. Am. 32 (1960), pp. 197-209.

[26] J.R. Birchak and S. Serabian, Calibration of ultrasonic systems for inspection from curved surfaces, Mater. Eval. 36 (1978), pp. 39-44.

[27] K. Endo, Practical observations of initiation and propagation of fretting fatigue cracks, in Fretting Fatigue, R.B. Waterhouse, ed., Applied Science Publishers Ltd, London, 1981, pp. 127-141.

[28] S. Faanes, Inclined cracks in fretting fatigue, Eng. Fract. Mech. 52 (1995), pp. 71-82. 